\section{A CASE OF INTRINSIC CANCER OF THE} LARYNX TREATED BY THYROTOMY.

BY J. DUND.S GR.ANT, M.A., M.D., F.R.C.S.ENG., surce a to tle Central London Throat and Ear Hospital.

(i. B. L., aged 50, was admitted under my care on August 23rd, 1890, complaining of loss of voice. He is a tall thin man, somewhat pale and anxious-looking, but on the whole fairly well nourished. He had had no previous disease of any seriousness, but at the age of 18 began to suffer from palmar eczema, which lasted for five years. His occupation, that of an undertaker, had led to considerable exposure in all kinds of weather, resulting in many slight catarrhal attacks. In youth he was a tobacconist's assistant, but he does not smoke. He had always been very abstemious in regard to alcohol. There was no evidence of gout, rheumatism, or specific disease. His family history is good; his father, aged 74 , being still alive and healthy, his mother having died of paralysis at the age of 68 , his brothers and sisters being all healthy.

His present illness commenced at Christmas, 1889, with a slight cold. This was followed by hoarseness, which gradually increased till his voice was completely lost, about six weeks before admission. There has been no cough or sweat-

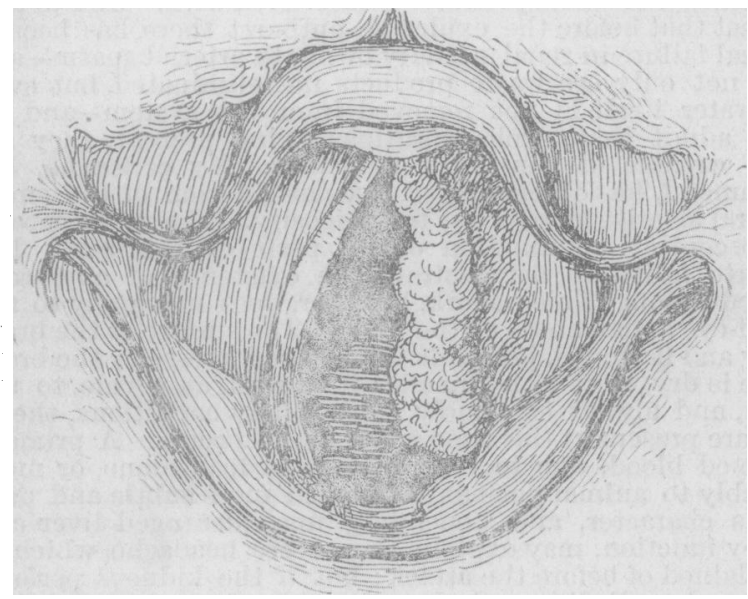

Fig. 1.

ing, but he has lost $14 \mathrm{lbs}$. in weight since April, when he weighed 11 stone. He has not experienced any difficulty in breathing nor swallowing, neither has there been any pain until within the last few weeks, during which he has noticed a "shooting" pain running up to the left ear.

On admission his voice was a mere whisper; he had no cough, and his respiration and deglutition were normal. His weight was 10 stone. (On palpation of the larynx there was just sufficient fulness of the left ala of the thyroid cartilage to enable one to suspect that there was disease of the left half rather than of the right half of the larynx.

On laryngoscopic examination, the whole of the left vocal cord was seen to be replaced by a nodular mass of a pale coral pink colour. This extended also to the ventricular band, which was much swollen and congested. The mass projected beyond the middle line, and was quite immobile during pronation and inspiration. Apparently the disease extended some distance below the glottis. The right cord was somewhat congested, but moved well, and the ventricular band was thickened and congested, apparently in continuation with the disease on the opposite side (Fig. 1). There was a very slight sensation of fulness in the region of the glands over the carotid artery at the level of the thyroid cartilage on the left side.

On August 25th I removed, with forceps, a small portion of the growth, about the size of a split pea; this was frozen and cut, six hours afterwards, by Mr. W. Wingrave, and was found to consist of well-marked "cell-nest" formation of stratified epithelioma, confirming the diagnosis first made by Dr. Gordon Holmes, who had previously seen the case (Fig. 2).
Operation.-On August 27th, at 8 A.M., chloroform being administered by Mr. Wingrave, I performed tracheotomy through the two upper rings of the trachea. This was accomplished, with Dr. Orwin's assistance, almost without hæmorrhage, after the principle-so prominently laid down by Mr. R. W. Parkerof lifting up the tissues by means of two pairs of dissecting forceps used at the corresponding position on the two sides of the middle line. Hahn's "tampon cannula" was then inserted, and left in position for twenty minutes to allow for its expansion. This, however, took place only imperfectly, as the sponge had been prepared too long in advance. The patient was noticed to breathe to some extent through the nose during the operation, but by far the greater volume of air passed by the tube. A considerable quantity of blood was inhaled into the air tubes. I then proceeded to perform thyrotomy with the aid of $\mathbf{M r}$. Lennox Browne and other colleagues. The thyroid cartilage was exposed by means of an incision continuous with the tracheal wound. The soft tissues above the notch having been redressed, the angle was divided with pliers, the alæ separated, and a complete view of the interior of the larynx was obtained, showing that the growth was (as suspected) more extensive than was indicated by the laryngoscope. It occupied the greater part of the left ventricular band and vocal cord, extending below the latter. There was also much thickening of the right band and cord, highly suggestive of extension to that side, so that it was deemed expedient to

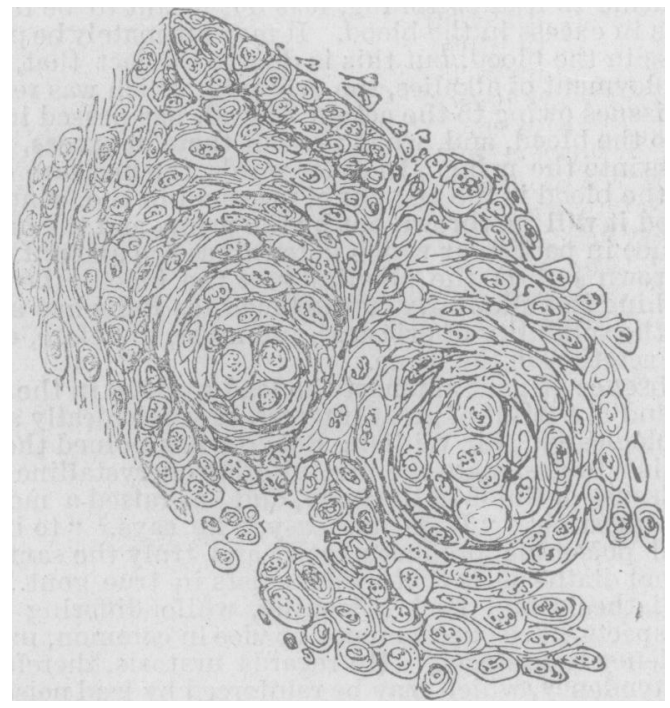

Fin. 2.

remove the whole of the interior of the larynx, as recommended by Mr. Butlin. This was done by means of a raspatory and blunt-pointed scissors, care being taken to preserve intact the laryngo-pharyngeal orifice. The crico-thyroid artery was divided, but there was no other hæmorrhage of much importance. The cartilages were scraped quite bare, the whole interior of the larynx was thoroughly swabbed with a strong solution of chloride of zinc, and then insufflated with iodoform. After the alæe were wired together, a drainage tube was placed so that it projected through the upper and lower extremities of the incision, and the wound was closed by four sutures. The surface of the wound was dusted with iodoform, and blue sal alembroth wool dressing was applied. The patient was under chloroform nearly two hours, and bore it very well, but towards the end he appeared somewhat collapsed. However, he speedily recovered after the hypodermic injection of ether. He was then put to bed, a restorative dose of brandy and beef-tea was administered per rectum, and a steam kettle containing some eucalyptus oil was kept playing in the room.

At 3 P.M. he was very comfortable, and was fed by means of an csophageal tube with brandy and beef-tea mixture A small gum elastic tube $\dot{a}$ boule was first used, but it caused great discomfort, coughing, and hæmorrhage; 
therefore a thick india-rubber (Jaques) tube was substituted, and the feeding was accomplished with ease and comfort. $\mathrm{He}$ complained of slight soreness of the throat, his temperature was $100.5^{\circ}$, and the pulse 72 . At 8 P.M. he was fed per rectum; temperature $101.5^{\circ}$, pulse 84 .

August 28th. He slept fairly well, again fed by tube. Hahn's cannula was removed, and replaced by an ordinary tracheal tube, which was more comfortable to the patient. He spat up large quantities of bloodstained mucus, and had a slight cough. He complained of great thirst, which was relieved to some extent by the very small quantities of ice he was allowed to suck. Every four hours 20 drops of solution of hydrarg. biniod. (1 per 1.000) was administered by the mouth, as a local and general antiseptic, a few drops entering the larynx during deglutition. Râles were heard over the left base. Morning temperature $99.5^{\circ}$, evening temperature $101^{\circ}$.

August 29th. Slept well; was again fed by tube and an enema; thirst very troublesome; chest clear; expectoration mucus very slightly stained; morning temperature $99^{\circ}$; evening temperature $100.8^{\circ}$.

August 30th. Enjoyed the lean" part of a mutton chop, which, with some water, he swallowed with ease; he takes milk freely; tracheal tube changed, and drainage tube removed; thirst less; morning temperature $98^{\circ}$; evening temperature $99.2^{\circ}$.

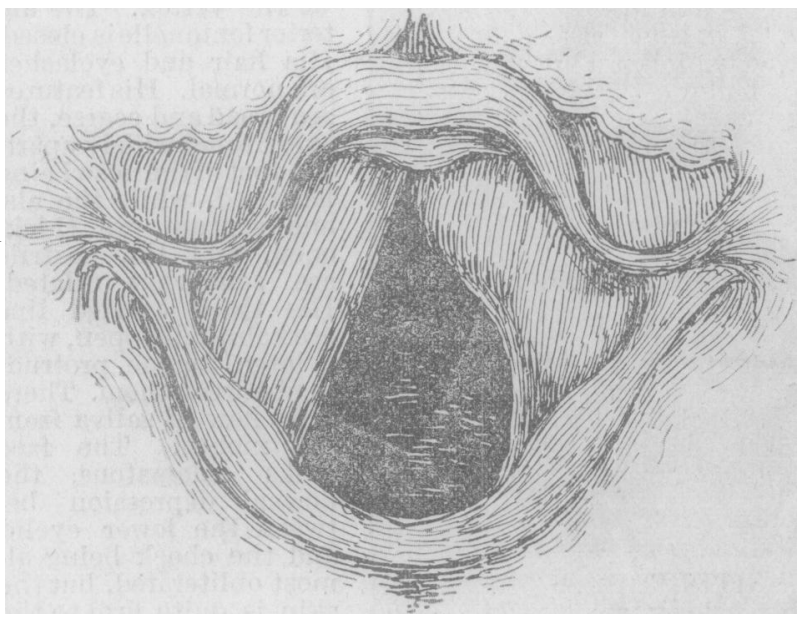

Fig. 3.

August 31st. Slept well : thirst relieved entirely ; abundant muco-purulint expectoration; morning temperature $98^{\circ}$; evening temperature $99^{\circ}$.

September 1st. A restless night; cough very troublesome; a few riles over the left base: feels depressed and dislikes food. Urine contained an excess of phosphates, otherwise normal. Is bowels had not been relieved since the operation, he was ordered hydrarg. subchlor gr.ij. The tube was changed. Morning temperature $98^{\circ}$; evening temperature $99.8^{\circ}$.

September 2nd. Slept better. Bowels not having been relieved, hydrarg. subchlor. gr.iij was ordered.

September 3rd. Slept six hours. Cough less troublesome; expectoration fretid; bowels relieved; appetite better. The superficial stitches were removed. Morning temperature $98^{\circ}$; evening tempera ure $99.6^{\circ}$

From this date his recovery was uninterrupted. On the 5th he coughed up a small portion of necrosed cartilage. The cough and expectoration gradually decreased, the temperature remained normal, and the patient rapidly regained his health and spirits. ( $n$ the 8 th the tube was permanently removed, and the cough ceased almost immediately. On the 14th the tracheotomy wound was closed, and on the 19th the patient went out for a short walk.

He was discharged from the hospital on the $22 \mathrm{nd}$ in the following condition: His weight 10 stone $1 \mathrm{lb}$, , felt strong and hearty; his complexion good, his expression bright and cheerful. Laryngoscopic examination showed on the right side an arrangement of the lining membrane singularly like a new vocal cord, and which moved on phonation; the left side was occupied by a cushionlike fulness covered with a healthylooking mucous membrane (Fig. 3). The voice was a good strong whisper, his deglutition was perfect. The glandular swelling was certainly no larger, and the pain running up to the left ear no longer felt.

The parts removed were examined by Mr. Wingrave, with the following results: The right hand and cord were hyperæmic, but showed no signs of growth, which was confined to the left side, and in this situation was composed of rapidly growing stratified epithelioma, involving the sacculus and ventricle, but not extending beyond the left arytenoid cartilage in the direction of the middle line.

In this case the difficulties in diagnosis were comparatively slight, as the typical appearance of the unilateral ulceration, accompanied by immobility of the vocal cord, offered a laryngoscopic picture which hardly admitted of doubt. The age of the patient, the pain shooting up to the ear, and the progress of the disease, strongly favoured the idea of carcinoma, which was absolutely confirmed by the result of the microscopical examination of the fragment removed with the forceps. It is true these microscopical appearances were not utterly incompatible with the possibility of the portion examined being the apex of a papilloma. This was, however, excluded by the laryngoscopic signs, and notably by the fixation of the vocal cord. In the same way tubercle and syphilis were eliminated.

The comparative inefficiency of Hahn's arlmirable tamponcannula was unquestionably due to the long time that the sponge had been kept in a compressed state, and much anxiety was occasioned by the knowledge that a considerable quantity of blood and discharge, as well as some of the fluid food administered even by a carefully used tube, must have entered the bronchi luring the period which elapsed prior to the re-establishment of the function of the sphincter laryngis. How far the satisfactory progress of the case, in spite of this defect, was due to the minor details of after-treatment, is difficult to decide. The free use of antiseptic clressings in the form of iodoform and of alembroth gauze, the frequent use of iodide solution by syringe through the drainage tube as well by the mouth, the continual impregnation of the inspired air with steam charged with eucalyptus, no doubt were important factors. As regards feeding the combination of alimentation by cesophageal tube in the middle of the day, with that by enema night and morning, appeared to satisfy the nutritive requirements of the patient with a minimal disturbance of the affected parts, it being generally agreed that rectal feeding alone is insufficient.

The question of recurrence can only be answered by a further observation. Meanwhile, the patient has stecred clear of the dangers immediately incident to the operation.

Note on March 9th, 1891.-The patient continues well and hearty and pursues his ordinary avocation. He is free from pain, and as regards breathing and deglutition is apparently well. The glandular enlargement is no longer perceptible. His voice, a gruff whisper, is louder than on the occasion of the last note. On laryngoscopic examination, the appearance is as before, with this difference: that during phonation the tissues forming the side walls of the infundibulum of the larynx bulge more towards each other, especially in their anterior parts, so that a better approximation to a vibrating anteris is obtained and a louder vocal sound is produced. The left arytenoid cartilage still remains fixed. There is no sign of ulceration, and so far-six months-the patient seems free from recurrence.

Soxre particulars of the affray in which Dr. George Baird, one of the best known physicians in Wheeling, West Virginia, was shot and almost instantly killed by Dr. (ieorge L. Garrison, "ex-city health officer and a physician of high standing," are given in the Medical Record of New York (March 1.th). The two physicians had been intimate friends, and when Dr. Garrison was appointed health officer Dr. Baird performed his duties without remuneration while Dr. Garrison was absent at the Collere. About a year ago Dr. Garrison obtained a warrant for the arrest of Dr. Baird, charging him with violation of the law as to a death certificate. The feud thus originated had a tragic end in the murder of Dr. Baird. 